\title{
The effect of starter culture and annatto on the flavor and functionality of whey protein concentrate
}

\author{
R. E. Campbell, R. E. Miracle, and M. A. Drake ${ }^{1}$ \\ Department of Food, Bioprocessing and Nutrition Sciences, Southeast Dairy Foods Research Center, North Carolina State University, \\ Raleigh 27695
}

\begin{abstract}
The flavor of whey protein can carry over into ingredient applications and negatively influence consumer acceptance. Understanding sources of flavors in whey protein is crucial to minimize flavor. The objective of this study was to evaluate the effect of annatto color and starter culture on the flavor and functionality of whey protein concentrate (WPC). Cheddar cheese whey with and without annatto $(15 \mathrm{~mL}$ of annatto $/ 454 \mathrm{~kg}$ of milk, annatto with $3 \% \mathrm{wt} /$ vol norbixin content) was manufactured using a mesophilic lactic starter culture or by addition of lactic acid and rennet (rennet set). Pasteurized fat-separated whey was then ultrafiltered and spray dried into WPC. The experiment was replicated 4 times. Flavor of liquid wheys and WPC were evaluated by sensory and instrumental volatile analyses. In addition to flavor evaluations on WPC, color analysis (Hunter Lab and norbixin extraction) and functionality tests (solubility and heat stability) also were performed. Both main effects (annatto, starter) and interactions were investigated. No differences in sensory properties or functionality were observed among WPC. Lipid oxidation compounds were higher in WPC manufactured from whey with starter culture compared with WPC from rennet-set whey. The WPC with annatto had higher concentrations of $p$-xylene, diacetyl, pentanal, and decanal compared with WPC without annatto. Interactions were observed between starter and annatto for hexanal, suggesting that annatto may have an antioxidant effect when present in whey made with starter culture. Results suggest that annatto has a no effect on whey protein flavor, but that the starter culture has a large influence on the oxidative stability of whey.
\end{abstract}

Key words: annatto, flavor, starter culture, whey protein

Received September 6, 2010.

Accepted November 9, 2010.

${ }^{1}$ Corresponding author: maryanne_drake@ncsu.edu

\section{INTRODUCTION}

Whey and dried whey ingredients are expected to have a delicate and bland flavor that is undetectable in finished goods (Drake, 2006). Flavors that carry through to the finished product limit the utilization of whey protein as a desired ingredient. Factors that influence the flavor of fluid whey and whey protein include cheese type (Liaw et al., 2010), storage conditions of fluid and dried products (Drake et al., 2009; Wright et al., 2009; Liaw et al., 2010), variability among processing plants (Carunchia Whetstine et al., 2003), and bleaching (Croissant et al., 2009). A combination of consumer demand for yellow Cheddar cheese and a manufacturer ingredient demand for bland, neutral-colored whey protein concentrate (WPC) makes bleaching a necessary step during dried whey ingredient production (Croissant et al., 2009; Kang et al., 2010). Although limited research has been done on the influence of bleaching on WPC flavor, no research has been done on the influence of annatto itself on WPC flavor. Annatto, which is composed of the carotenoids bixin and norbixin, is a natural food colorant used to color Cheddar cheese. One previous study has been conducted on the volatile composition of annatto, but this was only conducted on the extracts themselves and not in a food matrix, such as whey (Galindo-Cuspinera et al., 2002).

Whey products made from different types of cheeses have different flavors (Carunchia Whetstine et al., 2003; Drake et al., 2009). The flavor from thermophilic starters differs from the flavor of whey mesophilic starter cultures, and the flavor of whey from acid-set curd differs even further, although few studies have directly, quantitatively addressed this topic (Drake et al., 2009). Wheys produced from rennet-set cheese were described as bland, sweet, and milky, whereas wheys from acid casein were described as bitter, stale, rancid, and chemical (Gallardo-Escamilla et al., 2005). Within acid whey products, sensory differences were perceived in directly acidified milk and whey and those from fermentation (Gallardo-Escamilla et al., 2005). Lactococcus lactis starter cultures, used to produce Cheddar cheese, influence flavor and oxidative stability of liquid 
whey compared with whey manufactured using direct acidification (Tomaino et al., 2004). Wright et al. (2009) documented distinct flavors and volatile compounds in Mozzarella WPC 80\% protein compared with Cheddar WPC $80 \%$ protein from different commercial sources. Liaw et al. (2010) confirmed that distinct volatile compounds were observed between Cheddar and Mozzarella liquid whey from the same milk source. The influence of starter culture and annatto on the flavor and functionality of WPC has not been evaluated. The objective of this study was to evaluate the effect of annatto color and starter culture on the flavor and functionality of WPC.

\section{MATERIALS AND METHODS}

\section{Experimental Design Overview}

A $2 \times 2$ factorial design (starter, no starter, annatto, no annatto) was employed from the same lot of pasteurized milk to produce all 4 treatments. The order of production was randomized and production took place over $2 \mathrm{~d}$. Cheddar cheese whey with and without annatto was manufactured using a mesophilic lactic starter culture or by addition of acid and rennet. Pasteurized fat-separated whey was then ultrafiltered and spray dried into WPC with $62 \%$ protein. The experiment was replicated 4 times. The flavor of liquid wheys was evaluated by sensory and instrumental volatile analysis. Retentate, before spray drying, was subjected to instrumental volatile compound analysis. Sensory and instrumental analyses, color analysis (Hunter Lab and norbixin), and functionality tests (solubility and heat stability) were performed on WPC.

\section{Production of WPC}

Whole, raw bovine milk (390 kg) was received from the North Carolina State University Dairy Education Unit in Raleigh. Milk was pasteurized at $63^{\circ} \mathrm{C}$ for 30 min in a pasteurization vat (model MPD1050, Micro Process Design, D \& F Equipment Co., McLeansville, NC). Milk was cooled and refrigerated at $4^{\circ} \mathrm{C}$ overnight for processing the next day. Four treatments of WPC (culture with annatto, culture without annatto, acid with annatto, acid without annatto) were manufactured across a 2-d period from this lot of milk.

The pasteurized milk was heated to $31^{\circ} \mathrm{C}$ in a 250 $\mathrm{kg}$ cheese vat (model MX4, Kusel Equipment Co., Watertown, WI). For treatments with added starter culture, the milk was inoculated with a freeze-dried lactic acid starter culture $(50 \mathrm{DCU} / 454 \mathrm{~kg}$, Choozit MA 11, Danisco, New Century, NJ). Next, calcium chloride solution (50\% wt/vol; Dairy Connection Inc.,
Madison, WI) was added at the rate of $0.39 \mathrm{~mL} / \mathrm{kg}$ of milk. The milk was agitated and allowed to ripen for 60 min. After 30 min of ripening, double-strength annatto color $(3 \%$ norbixin wt/vol; Danisco) was added at 15 $\mathrm{mL} / 454 \mathrm{~kg}$ of milk and diluted 20 times in deionized (DI) water if the treatment called for the addition of annatto. Samples were allowed to finish ripening and if the treatment did not contain culture, the $\mathrm{pH}$ was adjusted to 6.40 using a 1:10 dilution of lactic acid ( $85 \%$ wt/vol; Fisher Scientific, Pittsburgh, PA) and DI water. Then, the milk was coagulated with doublestrength recombinant rennet (Dairy Connection Inc., Madison, WI) for $30 \mathrm{~min}$ at a rate of $0.09 \mathrm{~mL} / \mathrm{kg}$ of milk diluted 80 times in DI water. The coagulum was cut with $0.95-\mathrm{cm}$ wire knives, and the curd and whey were allowed to rest for $5 \mathrm{~min}$ followed by gentle stirring for $10 \mathrm{~min}$ without added heat. The temperature was increased gradually from 31 to $39^{\circ} \mathrm{C}$ over $30 \mathrm{~min}$ while $\mathrm{pH}$ and titratable acidity were closely monitored. The curd was continuously stirred at $39^{\circ} \mathrm{C}$ until the target whey drain $\mathrm{pH}$ of 6.40 was attained. As the whey was drained, a sieve was used to remove any remaining particles and the whey was immediately pasteurized at $63^{\circ} \mathrm{C}$ for $30 \mathrm{~min}$. The hot whey was immediately processed with a cream separator (model FJ 125 EAR hot-bowl cream separator, Clair, Althofen, Austria) to reduce the fat content. Total solids and fat content percentage of fluid milk and whey were analyzed using the Smart System 5 moisture/solids analyzer with SmartTrac rapid fat analysis (CEM, Matthews, NC). Percent solids measurements also were recorded with the CEM apparatus.

Pasteurized, separated whey was weighed and placed in $60 \mathrm{~L}$ stainless steel containers (model 601BP, Polar Ware Co., Kiel, WI). The whey was then concentrated using a UF system (model Pellicon 2, Millipore Inc., Billerica, MA) equipped with 3 polyethersulfone cartridge membrane filters (model P2B010V05; nominal separation cutoff: 10,000 kDa, surface area: $0.5 \mathrm{~m}^{2}$ ). A variable-speed peristaltic pump (model 77410-10) equipped with model 77601-00 pumpheads with silicone tubing (model 96440-73) was used to circulate the product. Pumps, pumpheads, and tubing were obtained from Cole-Palmer (Vernon Hills, IL). Each sample was run through a separate pump head and UF assembly. Samples were maintained at $50^{\circ} \mathrm{C}$ using a circular immersion heater (model 356K05K73, McMaster-Carr, Atlanta, GA) while being processed on the UF system. Permeate was collected and the UF process continued until 20 to $22 \%$ solids (wt/vol) was reached. The weights of both the permeate and the retentate were recorded. The total UF time varied from 3 to $6 \mathrm{~h}$. The final liquid UF retentate was then spray dried (model Lab 1, Anhydro Inc., Soeberg, Denmark). The total time for 
drying was approximately $2 \mathrm{~h}$. Powders were sealed in Mylar bags and stored at $-80^{\circ} \mathrm{C}$. This experiment was replicated 4 times.

\section{Composition Analysis of WPC}

Total solids of WPC were determined by air oven drying (AOAC, 2000; method number 990.20; 33.2.44). Fat was quantified by ether extraction (AOAC, 2000; method number 989.05; 33.2.26). Protein was determined using the Kjeldahl method (AOAC, 2000; method number 991.20; 33.2.11). Mineral analysis (phosphorus, calcium, magnesium, potassium, sulfur, sodium, and iron) was determined by the NCSU Analytical Services Laboratory (Raleigh, NC) using a standard dry ash method with inductively coupled plasma optical emission spectroscopy (Lloyd et al., 2009). All samples were measured in duplicate.

\section{Annatto Extraction}

Annatto extraction methods were modified from Croissant et al. (2009). One gram of dried whey protein was weighed into a $50-\mathrm{mL}$ centrifuge tube (Nalgene, Rochester, NY), and $2 \mathrm{~mL}$ of HPLC-grade water (EMD Chemicals Inc., Gibbstown, NJ) was added. This sample was then vortexed for $30 \mathrm{~s}$. To this, $6 \mathrm{~mL}$ of ethanol (EMD Chemicals Inc.) was added, vortexed for $30 \mathrm{~s}$, and allowed to stand for $30 \mathrm{~min}$. Three milliliters of chloroform (EMD Chemicals Inc.) was added and vortexed with centrifugation at $16,500 \times g$ for $10 \mathrm{~min}$ at $4^{\circ} \mathrm{C}$ (model RC5B, Thermo Scientific, Waltham, MA). The supernatant was removed to a separate centrifuge tube. To the remaining solids, $3 \mathrm{~mL}$ of chloroform was added, the sample was vortexed to ensure mixing, and centrifuged again at $16,500 \times g$ for $10 \mathrm{~min}$ at $4^{\circ} \mathrm{C}$. The bottom liquid layer was collected and added to the previously collected supernatant. Next, $2 \mathrm{~mL}$ of acetic acid (1\%) was added, vortexed for $30 \mathrm{~s}$, and centrifuged at $16,500 \times g$ for $10 \mathrm{~min}$. The bottom chloroform layer containing the norbixin was collected and the volume was measured. The extraction procedure and measurements were performed with premium, full-spectrum F885 flat-sheet filters covering all lights (Ergomart, Dallas, TX) to minimize norbixin isomerization and degradation (Mercadante, 2008).

To further filter and purify the norbixin, solid-phase extraction (SPE) was used. The column selected was the Strata- $\mathrm{NH}_{2} \mathrm{SPE}$ column $(500 \mathrm{mg} / 3 \mathrm{~mL}$, Phenomenex, Torrance, CA). To condition the column, $7 \mathrm{~mL}$ of $n$-hexane (VWR International, West Chester, PA) was run through the column. An aliquot of the extract collected previously $(1 \mathrm{~mL})$ was transferred onto the conditioned SPE column. The column was rinsed with
$5 \mathrm{~mL}$ of $n$-hexane:diethyl ether $(1: 1 \mathrm{vol} / \mathrm{vl})$ and $1 \mathrm{~mL}$ acetone (VWR International). The norbixin was eluted with $3 \mathrm{~mL}$ of methanol:glacial acetic acid (7:3 vol/vol). The final volume was recorded.

\section{Spectrophotometry}

To quantify norbixin, spectrophotometry was used (UV/Vis-spectrophotometer Cary 300 Bio, Varian, Cary, NC; Croissant et al., 2009). A 0.7-mL aliquot of each sample was measured in a 28Q10 Spectrosil quartz cuvette (Starna Cells, Inc., Atascadero, CA). A standard curve was created within the concentration range of $50 \mu \mathrm{g} / \mathrm{kg}$ to $3 \mathrm{mg} / \mathrm{kg}$ of norbixin. Norbixin powder (45\% wt/wt; Chr. Hansen, Milwaukee, WI) was rehydrated in $2.5 \%$ potassium hydroxide and then diluted in methanol:glacial acetic acid (7:3 vol/vol). Carotenoids generally have 3 peaks of absorption maxima (Levy and Rivadeneira, 2000). The maxima used for calculation was $458 \mathrm{~nm}$. The carotenoid concentration of the SPE extract was calculated using the standard curve. Norbixin concentration was expressed as milligrams of norbixin per kilograms of solids, calculated by total solids and correction for dilution during the extraction and SPE processes.

\section{Hunter $L^{*} a^{*} b^{*}$}

The color of WPC powders was measured using a Minolta Chroma meter (CR-410, Ramsey, NJ). Ten grams of WPC was placed into the bottom of a $60 \mathrm{~mm}$ $\times 15 \mathrm{~mm}$ polystyrene Petri dish in duplicate (Beckton Dickinson, Franklin Lakes, NJ). Each Petri dish was measured in triplicate. Prior to measurements being taken, a factory-supplied calibration plate was used to calibrate the instrument. The Hunter CIE Lab color scale was used.

\section{Volatile Compound Analysis (Solid-Phase Microextraction GC-MS)}

Volatile compounds in fluid whey, retentate, and whey protein powder were extracted by solid-phase microextraction. Compounds were then separated and identified by GC-MS using a modified method of Wright et al. (2009). Liquid samples were tested the day of manufacture and spray-dried powders were reconstituted at $10 \%$ solids (wt/vol) and evaluated within 7 d. All samples contained 10\% (wt/vol) sodium chloride (Fisher Scientific), and $10 \mu \mathrm{L}$ of internal standard solution (2-methyl-3-heptanone in methanol at $81 \mathrm{mg} / \mathrm{kg}$; Sigma Aldrich) in 20-mL autosampler vials with steel screw tops containing silicone septa faced in Teflon (Microliter Analytical, Suwanee, GA). Samples were 
injected using a CombiPal autosampler (CTC Analytics, Zwingen, Switzerland) attached to an Agilent 6890N GC with 5973 inert MSD (Agilent Technologies Inc., Santa Clara, CA). Samples were maintained at $5^{\circ} \mathrm{C}$ before fiber exposure. Samples were equilibrated at $40^{\circ} \mathrm{C}$ for $25 \mathrm{~min}$ before 30 -min fiber exposure of a 1 -cm divinylbenzene/carboxen/polydimethylsiloxane fiber (Supelco, Bellefonte, PA) at $31 \mathrm{~mm}$ with 4-s pulsed agitation at $250 \mathrm{rpm}$. Fibers were injected for $5 \mathrm{~min}$ at a depth of $50 \mathrm{~mm}$.

The GC method used an initial temperature of $40^{\circ} \mathrm{C}$ for 3 min with a ramp rate of $10^{\circ} \mathrm{C} / \mathrm{min}$ to $250^{\circ} \mathrm{C}$ held for $5 \mathrm{~min}$. Solid-phase microextraction fibers were introduced into the split/splitless injector at $250^{\circ} \mathrm{C}$. A Zb-5ms column (Zb- $5 \mathrm{~ms}, 30 \mathrm{~m}$ length $\times 0.25 \mathrm{~mm}$ i.d. $\times 0.25 \mu \mathrm{m}$ film thickness; Phenomenex) was used for all analyses at a constant flow rate of $1 \mathrm{~mL} / \mathrm{min}$. Purge time was set at $1 \mathrm{~min}$. The MS transfer line was maintained at $250^{\circ} \mathrm{C}$ with the quad at $150^{\circ} \mathrm{C}$ and source at $250^{\circ} \mathrm{C}$. Compounds were identified using the NIST 2005 library of spectra and by comparing to spectra of authentic standards injected under identical conditions. Relative abundance for each compound was calculated using the calculated recovery of the internal standard concentration to determine relative concentrations of each compound. Retention indices were calculated using an alkane series (Sigma Aldrich; Van den Dool and Kratz, 1963).

\section{Volatile FFA Analysis}

Volatile FFA in WPC were extracted and evaluated by solid-phase microextraction with GC using a modified method from Tomaino et al. (2004). Samples were rehydrated at $10 \%$ (wt/vol) in deionized water and the $\mathrm{pH}$ was adjusted to 2.0 with $3.3 M$ hydrochloric acid ( $20 \% \mathrm{vol} / \mathrm{vol}$, VWR). Five grams of the $\mathrm{pH}$ adjusted sample was added to a 20-mL autosampler vial with steel screw tops containing silicone septa faced in Teflon (Microliter Analytical). An internal standard, heptadecanoic acid $(1 \mathrm{mg} / \mathrm{kg}$ in ether; EMD Chemicals), was added at $5 \mu \mathrm{L}$ per vial. Each sample was run in triplicate. Samples were injected using a CombiPal autosampler (CTC Analytics) attached to a Varian CP-3380 gas chromatograph (Agilent Technologies). Samples were maintained at $10^{\circ} \mathrm{C}$ before fiber exposure. Samples were equilibrated at $110^{\circ} \mathrm{C}$ for $10 \mathrm{~min}$ before 40-min fiber exposure (22 $\mathrm{mm}$ vial penetration) of a $30-\mu \mathrm{m}$ polydimethylsiloxane fiber (Supelco) with 4-s pulsed agitation at $250 \mathrm{rpm}$. Fibers were injected for 10 min at a depth of $50 \mathrm{~mm}$.

The GC method used an initial temperature of $100^{\circ} \mathrm{C}$ for $2 \mathrm{~min}$ with a ramp rate of $10^{\circ} \mathrm{C} / \mathrm{min}$ to $245^{\circ} \mathrm{C}$ held for $13.5 \mathrm{~min}$. Helium flow rate was $1 \mathrm{~mL} / \mathrm{min}$ and solid- phase microextraction fibers were introduced into the split/splitless injector at $250^{\circ} \mathrm{C}$. A ZB-FFAP column $(30 \mathrm{~m}$ length $\times 0.25 \mathrm{~mm}$ i.d. $\times 0.25 \mu \mathrm{m}$ film thickness; Phenomenex) was used for all analyses.

Compounds were identified using authentic standards injected under identical conditions. Relative abundance for each compound was calculated using the calculated recovery of the internal standard concentration to determine relative concentrations of each compound.

\section{Descriptive Sensory Analysis}

Sensory testing was performed using a trained descriptive sensory panel and an established dairy flavor language (Drake et al., 2003, 2009). Panelists $(\mathrm{n}=8)$ each had more than $150 \mathrm{~h}$ of previous experience with the sensory analysis of fluid and dried whey products using the Spectrum descriptive analysis method (Meilgaard et al., 1999). All sensory testing was conducted in accordance with the NCSU Institutional Review Board for Human Subjects guidelines.

Liquid whey and reconstituted WPC (10\% solids) were both evaluated by placing $30-\mathrm{mL}$ samples in randomized 3-digit-coded, 60-mL lidded cups (Solo Cup Co., Champaign, IL). Preparations were conducted with overhead lights off to avoid exposure to light. Liquid whey samples were evaluated immediately after fat separation on the day of production at $21 \pm 2^{\circ} \mathrm{C}$. Whey powders were rehydrated in deionized water $(10 \%$ solids, wt/vol) and evaluated within $7 \mathrm{~d}$ of production. Samples were evaluated by each panelist in duplicate. Sensory data were collected on paper ballots or by using Compusense 5.0 (Compusense, Guelph, ON, Canada).

\section{Solubility}

Solubility was determined by established methods (Smith et al., 1985; Bouaouina et al., 2006) with modifications. Whey protein concentrate $(10 \% \mathrm{wt} / \mathrm{vol}$ protein) was hydrated in DI water ( $80 \%$ of total volume) with stirring $(200 \mathrm{rpm})$ for $6 \mathrm{~h}$ at room temperature $\left(22 \pm 2^{\circ} \mathrm{C}\right)$. The solutions were kept overnight at refrigeration temperature $\left(4^{\circ} \mathrm{C}\right)$ and brought up to room temperature the next day. Once at room temperature, the solutions were adjusted to a $\mathrm{pH}$ of $4.6( \pm .05)$ with $1 \mathrm{~N} \mathrm{HCl}(20 \% \mathrm{vol} / \mathrm{vol} ; \mathrm{VWR})$. The solutions were then adjusted to their final volume. The solutions were then centrifuged at $10,000 \times g$ for $15 \mathrm{~min}$. Solutions were analyzed before and after centrifugation (supernatant) by the Sprint Protein Analyzer (CEM, Matthews, NC). Protein solubility was calculated as follows:

Protein solubility $=100-[(\%$ Protein before $-\%$ Protein after $/ \%$ Protein before) $\times 100]$. 
Each sample was evaluated in duplicate and all measurements also were performed in duplicate.

\section{Heat Stability}

Heat stability was measured using a method modified from Britten et al. (1994). Whey protein concentrate (5\% wt/vol protein) was hydrated in deionized water ( $80 \%$ of total volume) with stirring (200 rpm) for $6 \mathrm{~h}$ at room temperature $\left(22 \pm 2^{\circ} \mathrm{C}\right)$. The solutions were kept overnight at refrigeration temperatures $\left(4^{\circ} \mathrm{C}\right)$ and brought up to room temperature the next day. Once at room temperature, the solutions were adjusted to a $\mathrm{pH}$ of $3.5( \pm 0.05)$ with $1 \mathrm{~N} \mathrm{HCl}(20 \% \mathrm{vol} / \mathrm{vol}$; VWR). The solutions were then adjusted to their final volume and heated to $80^{\circ} \mathrm{C}$ for 5 or $20 \mathrm{~min}$. After heating, the solutions were centrifuged at $10,000 \times g$ for $15 \mathrm{~min}$. Solutions were analyzed before and after centrifugation (supernatant) by the Sprint Protein Analyzer (CEM). Heat stability was determined by protein solubility before and after heating. Each sample was evaluated in duplicate and all measurements also were performed in duplicate.

\section{Statistical Analysis}

All data was analyzed by a 2-way ANOVA using a general linear model (PROC GLM) in SAS (Statistical Analysis Software, version 9.1, SAS Institute, Cary, NC). Both main effects and interaction effects were analyzed. Fixed effects were set type (culture vs. acid set) and annatto (with and without) and their interactions. Replication effects and all interactions with replication effects were designated random effects.

\section{RESULTS AND DISCUSSION}

\section{Composition}

The WPC powders were not significantly different in composition $(P>0.05)$, with fat averaging $4.8 \pm 2.0 \%$, protein $62.7 \pm 4.0 \%$, and moisture $3.2 \pm 1.5 \%$. Minerals were not distinct among samples $(P>0.05)$. Minerals measured included phosphorus $(0.58 \pm 0.01 \%)$, calcium $(0.83 \pm 0.02 \%)$, magnesium $(0.08 \pm 0.00 \%)$, potassium $(1.10 \pm 0.02 \%)$, sulfur $(0.75 \pm 0.01 \%)$, sodium $(2.9 \pm$ $0.10 \mathrm{ppm})$, and iron $(10.0 \pm 2.00 \mathrm{ppm})$.

\section{Annatto Extraction}

Samples with annatto had higher $(P<0.05)$ norbixin content than those that did not contain any added color (14.9 vs. $1.7 \mathrm{mg} / \mathrm{kg}$ ). The WPC without annatto added also had low norbixin values, probably due to other coextracted carotenoids that occur naturally in milk (Croissant et al., 2007). The culture-set WPC had higher norbixin values $(P<0.05)$ than the WPC produced without culture ( 8.7 vs. $7.9 \mathrm{mg} / \mathrm{kg}$ ). This may be because rather than the $\mathrm{pH}$ being slowly lowered by lactic acid bacteria like the culture-set treatment, the rennet-set treatment received a single dose of diluted lactic acid to lower the $\mathrm{pH}$, which may have led to the destruction of some of the annatto (Scotter, 2009). It also is possible that enzymatic activity from the culture may have protected the annatto from degradation in the whey by creating compounds that are more readily oxidized than annatto. Currently it is unknown if annatto binds to components in fluid whey.

\section{Sensory and Volatile Compound Analyses}

Lipid oxidation is the primary reason for the evolution of storage-related flavors in whey protein products, and lipid oxidation products tend to have very low flavor thresholds and are thus easily detected in dairy products (Frankel, 1998; Wright et al., 2009; Whitson et al., 2010). Lipid oxidation products are present in freshly manufactured dried whey proteins (Javidipour and Qian, 2008; Wright et al., 2009). Tomaino et al. (2004) and Liaw et al. (2010) demonstrated that lipid oxidation products were present in fluid whey and suggested that lipid oxidation was initiated during the cheesemaking procedure and that starter cultures initiated or enhanced this process. Previously, sensory profiles of fresh fluid Cheddar and Mozzarella wheys were distinct from each other, with Cheddar whey containing higher amounts of lipid oxidation products (Liaw et al., 2010). The sensory attributes of fresh liquid wheys in the current study with and without starter culture or with and without added annatto (less than $2 \mathrm{~h}$ after manufacture) were not different $(P>0.05)$. Wheys were characterized by sweet aromatic, cooked/milky, and diacetyl flavors and sweet and sour tastes, similar to previous studies (Liaw et al., 2010; results not shown). Sensory properties of the freshly manufactured WPC were not distinct $(P>0.05)$. The WPC were characterized by sweet aromatic and cooked/milky flavors with low cardboard flavor intensities and low astringency, also consistent with previous results (Croissant et al., 2009; results not shown).

Volatile compound analysis of the fresh liquid wheys revealed differences in only 2 compounds. Limonene and $\alpha$-pinene were higher in fluid wheys made with annatto compared with those made without annatto, with mean values averaging 0.028 versus $0.009 \mu \mathrm{g} /$ kgand 0.021 versus $0.005 \mu \mathrm{g} / \mathrm{kg}$, respectively $(P<$ 0.05 ). These 2 compounds are likely due to the presence of annatto and have been previously documented in 


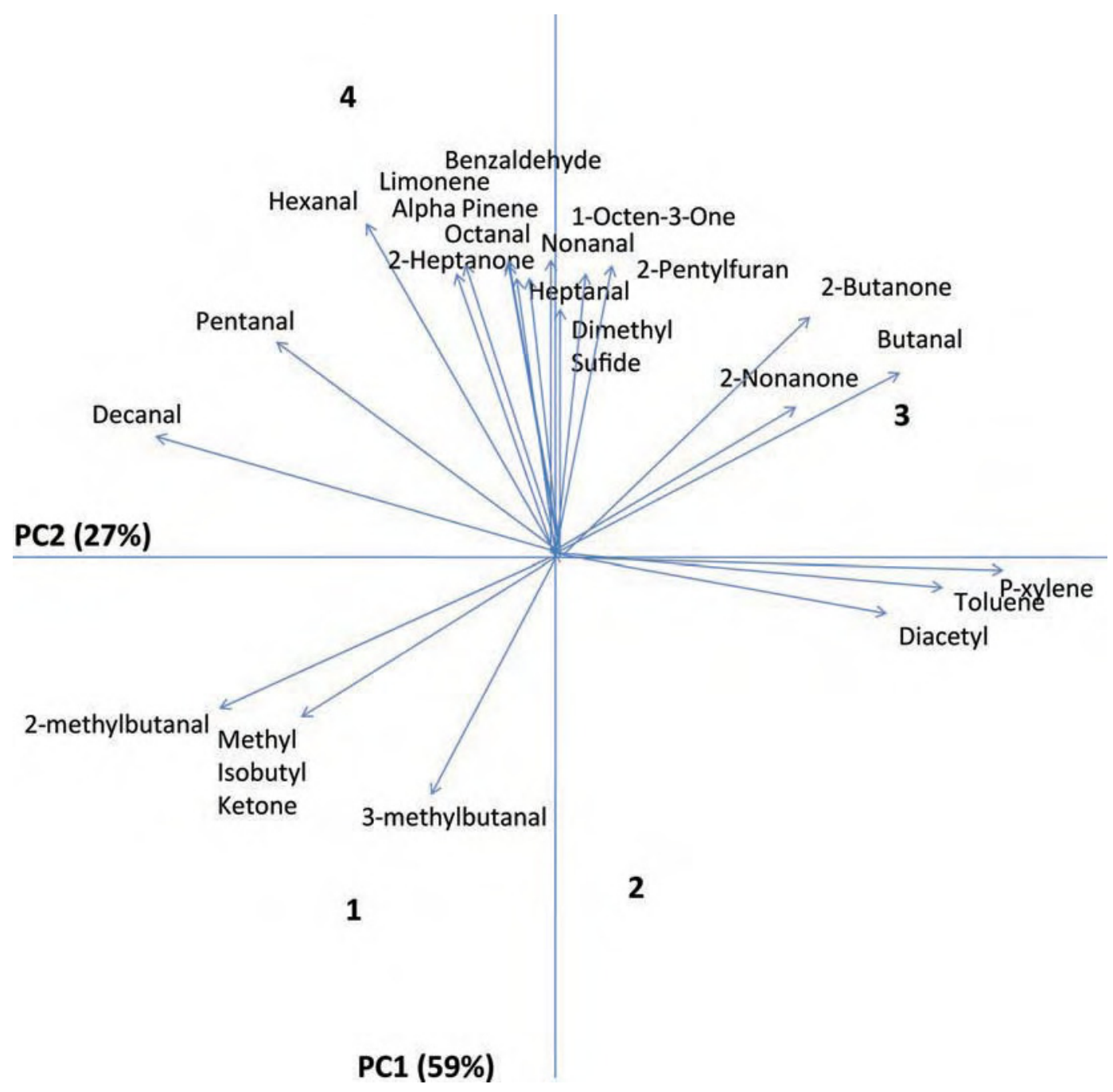

Figure 1. Principal component (PC) biplot of selected volatiles in whey protein concentrate extracted by solid-phase microextraction $(1=$ acid, no annatto, 2 = acid with annatto, $3=$ culture with annatto, $4=$ culture, no annatto). Color version available in the online PDF.

commercial annatto extracts (Galindo-Cuspinera et al., 2002). Volatile compound analysis also was conducted on the liquid whey retentate before spray drying with solids adjusted to $10 \%$ (wt/vol), and no differences were documented among the treatments $(P>0.05)$, nor were differences detected between liquid whey and liquid whey retentate $(P>0.05)$, except for diacetyl. Liquid whey contained higher concentrations of diacetyl $(P<$ 0.05) than retentate regardless of annatto or starter culture, with means averaging 1.26 versus $0.603 \mu \mathrm{g} / \mathrm{kg}$, respectively. This result may be attributed to the polarity of diacetyl as diacetyl is relatively polar and most likely washes out with the permeate during UF. Lipid oxidation products were present in all liquid wheys and retentates at very low levels $(<0.5 \mu \mathrm{g} / \mathrm{kg})$, which is consistent with previous research suggesting that lipid oxidation is initiated during the cheese-making process (Tomaino et al., 2004; Liaw et al., 2010).
In contrast to liquid whey and retentate results, differences were documented in volatile compounds of WPC $(P<0.05)$. Volatile lipid oxidation products were present in all WPC (Figure 1) and these products were present in higher amounts than documented in either the fluid whey or retentate before spray drying $(P<$ 0.05). The WPC made from starter culture whey (with or without annatto) had higher concentrations of hexanal than WPC from rennet-set whey (with or without annatto; 22.2 vs. $11.2 \mu \mathrm{g} / \mathrm{kg}, P<0.05$ ), as well as higher concentrations of 1-octen-3-ol and 2-nonanone $(0.779 \mu \mathrm{g} / \mathrm{kg}$ and $2.71 \mu \mathrm{g} / \mathrm{kg}$ vs. $0.543 \mu \mathrm{g} / \mathrm{kg}$ and 1.56 $\mu \mathrm{g} / \mathrm{kg}, P<0.05)$. Similarly, aldehydes, such as butanal, heptanal, and decanal also were higher $(P<0.05)$ and in relative abundance in the starter culture WPC compared with the rennet-set WPC (Table 1, Figure 1). Liaw et al. (2010) suggested that lipid oxidation products were dependent on culture type, with meso- 
Table 1. Relative abundance $(\mu \mathrm{g} / \mathrm{kg})$ of selected aldehydes in whey protein concentrate (with $62 \%$ protein) made with or without starter culture and with or without annatto

\begin{tabular}{lcccc}
\hline Aldehyde & $\begin{array}{c}\text { Acid, } \\
\text { annatto }\end{array}$ & $\begin{array}{c}\text { Acid, } \\
\text { no annatto }\end{array}$ & $\begin{array}{c}\text { Culture, } \\
\text { annatto }\end{array}$ & $\begin{array}{c}\text { Culture, } \\
\text { no annatto }\end{array}$ \\
\hline Butanal & $0.668^{\mathrm{b}}$ & $0.362^{\mathrm{b}}$ & $2.29^{\mathrm{a}}$ & $1.21^{\mathrm{ab}}$ \\
Pentanal & $0.215^{\mathrm{b}}$ & $0.236^{\mathrm{b}}$ & $0.164^{\mathrm{b}}$ & $0.659^{\mathrm{a}}$ \\
Hexanal & $12.8^{\mathrm{b}}$ & $9.92^{\mathrm{b}}$ & $12.3^{\mathrm{b}}$ & $33.8^{\mathrm{a}}$ \\
Heptanal & $1.54^{\mathrm{b}}$ & $1.29^{\mathrm{b}}$ & $2.05^{\mathrm{ab}}$ & $2.99^{\mathrm{a}}$ \\
Nonanal & $3.83^{\mathrm{a}}$ & $4.01^{\mathrm{a}}$ & $5.81^{\mathrm{a}}$ & $7.05^{\mathrm{a}}$ \\
Octanal & $0.604^{\mathrm{a}}$ & $0.450^{\mathrm{a}}$ & $0.698^{\mathrm{a}}$ & $0.995^{\mathrm{a}}$ \\
Decanal & $0.162^{\mathrm{ab}}$ & $0.196^{\mathrm{ab}}$ & $0.118^{\mathrm{b}}$ & $0.254^{\mathrm{a}}$ \\
\hline
\end{tabular}

${ }^{\mathrm{a}, \mathrm{b}}$ Means in a row not sharing a common superscript are different $(P<0.05)$.

philic starters producing more oxidation products than thermophilic starters.

The WPC with added annatto contained higher concentrations of decanal, $p$-xylene, 2-butanone, and pentanal than their uncolored counterparts $(P>0.05)$ (Figure 1). $p$-Xylene has been documented as a volatile from annatto (Galindo-Cuspinera et al., 2002). No study to our knowledge has been conducted to document annatto-related volatiles in a food matrix and it is likely that decanal, 2-butanone, and pentanal, as lipid oxidation products, are present at higher concentrations in products with annatto due to the influence of annatto on the lipid oxidation process in WPC. The WPC from starter culture whey with added annatto had lower concentrations $(P<0.05)$ of lipid oxidation products than the WPC from starter culture whey without added annatto, suggesting possible antioxidant activity from the annatto (Figure 1). Antioxidant effects of carotenoids are thought to be mainly from the carotenoids' ability to scavenge free radicals and efficiently quench singlet oxygen. Studies conducted on the antioxidant activity of annatto have been primarily conducted on bixin, with only 1 paper exploring norbixin (Kiokias and Gordon, 2003). Norbixin has been previously documented to retard oxidative deterioration of lipids in oil-in-water emulsions (Kiokias and Gordon, 2003).

\section{Volatile FFA}

The WPC made with culture and annatto had the highest levels of volatile FFA $(P<0.05)$ (Figure 2$)$. The other 3 samples were similar to each other $(P>0.05)$ and were characterized by lower levels of volatile FFA. Free fatty acids are present in most biological systems, including milk, in very small amounts (Cadwallader et al., 2007). Additional FFA can come from triglycerides that have undergone lipolysis. Lipases can originate from a variety of sources including milk, rennet paste, starter bacteria, secondary starter microorganisms, nonstarter lactic acid bacteria, and exogenous lipase preparations (Collins et al., 2004). Free fatty acids break down to form volatile lipid oxidation compounds such as methyl ketones, lactones, esters, alkanes, secondary alcohols and aldehydes (Collins et al., 2004). Previous studies, as well as the current study, suggest that the mesophilic starter culture is initiating oxidation and this process initiates with the generation of FFA. It is likely that the culture set sample made with annatto had higher levels of FFA because the FFA have yet to break down into other volatiles due to the antioxidant effect of annatto.

\section{Functionality}

No significant differences due to either addition of culture or annatto $(P>0.05)$ were found in the solubility or the heat stability of WPC. Solubility is a prerequisite for other functional properties, such as foaming, emulsifying, and gelling (deWit and Klarenbeek, 1984) and complete solubility is necessary for optimal functionality. All WPC had excellent solubility $(>95 \%)$ at the $\mathrm{pH}(4.6)$ tested. This $\mathrm{pH}$ is near the isoelectric point, where the net charge of the protein is minimal; thus protein interactions are favored, resulting in minimal solubility (Jayaprakasha and Brueckner, 1999). When whey proteins are heated above $70^{\circ} \mathrm{C}$, they are susceptible to thermal denaturation. This can cause partial loss of solubility between $\mathrm{pH} 3$ and 5 due to protein aggregation and precipitation (Jayaprakasha and Brueckner, 1999). Neither culture nor annatto had any effect on the heat stability of the WPC in this study $(P>0.05)$.

\section{CONCLUSIONS}

Dried whey protein, such as WPC or whey protein isolate are desired to be flavorless; however, this is rarely the case. Flavor and flavor variability can influence not only the quality of the product, but also consumer acceptance. This study investigated whether culture or annatto had an effect on functional or sensory properties of WPC and investigated lipid oxidation in the cheese- 


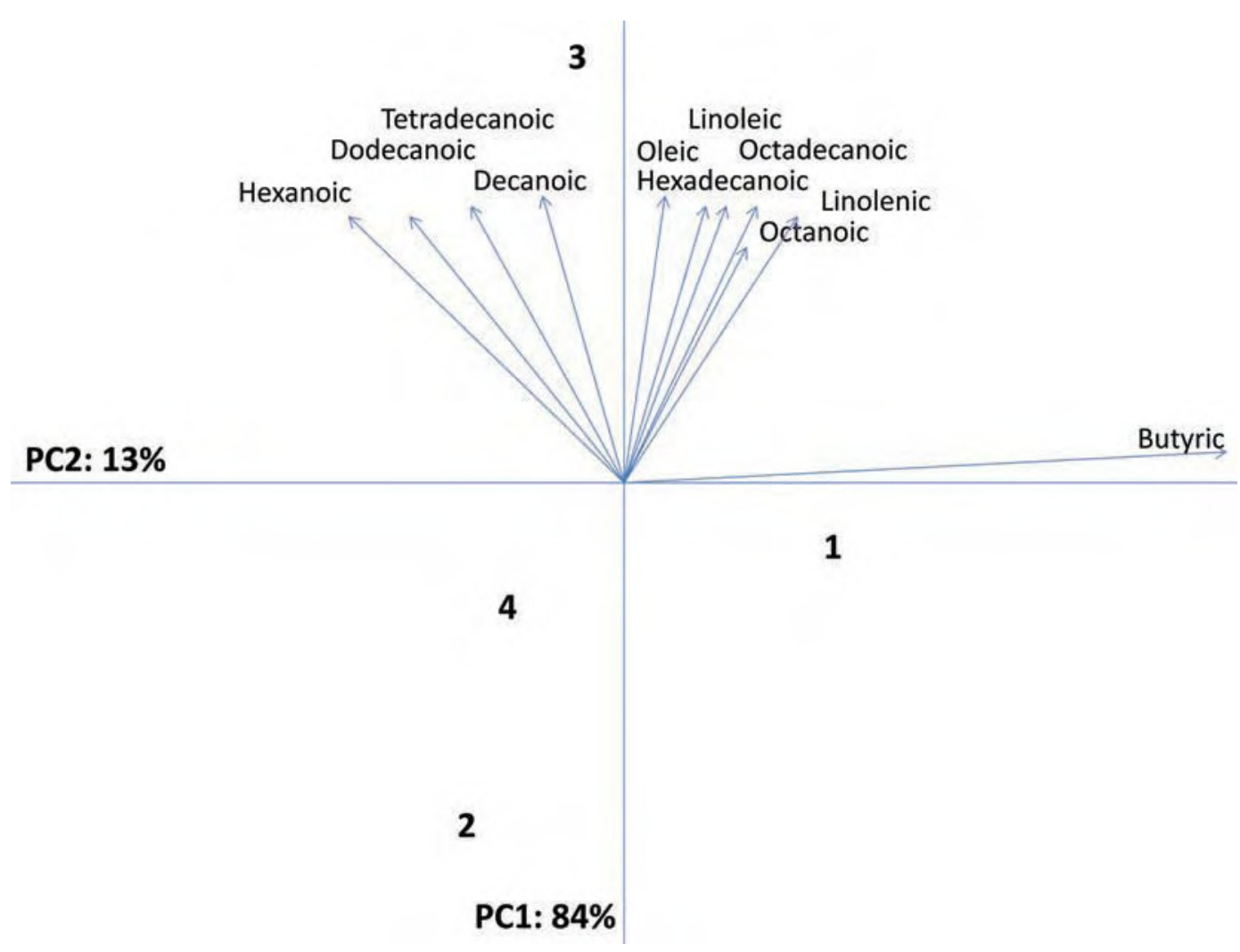

Figure 2. Principal component (PC) biplot of volatile FFA from whey protein concentrate $(1=$ acid, no annatto, $2=$ acid with annatto, 3 $=$ culture with annatto, $4=$ culture, no annatto). Color version available in the online PDF.

making process. Neither culture nor annatto had an effect on the functional properties of WPC $(P>0.05)$. Descriptive analysis of both WPC and fresh liquid whey did not indicate differences between samples $(P>0.05)$. Volatile compound analysis results confirmed that lipid oxidation products were present in all samples, even the fresh liquid whey, indicating that lipid oxidation begins during the cheese-making process. Lipid oxidation compounds were higher $(P<0.05)$ in WPC manufactured from whey with starter culture compared with WPC from rennet-set whey. Whey protein concentrate with annatto had higher concentrations of $p$-xylene, diacetyl, pentanal, and decanal $(P<0.05)$ compared with WPC without annatto. Interactions $(P<0.05)$ were observed between starter and annatto for hexanal, suggesting that annatto may have an antioxidant effect when present in whey made with starter culture. Further studies are needed to understand fully how to minimize lipid oxidation products in liquid whey.

\section{ACKNOWLEDGMENTS}

Funding provided in part by Dairy Management Inc. (Rosemont, IL). Paper FSR 10-37 of the journal series of the Department of Food, Bioprocessing and Nutrition Sciences, North Carolina State University (Raleigh). The advice and assistance of D. Barbano (Cornell University, Ithaca, NY) and B. Nelson (Daisy Brand, Dallas, TX) are gratefully acknowledged. The use of tradenames does not imply endorsement nor lack of endorsement of those not mentioned.

\section{REFERENCES}

AOAC. 2000. Official Methods of Analysis. 17th ed. Association of Official Analytical Chemists, Gaithersburg, MD.

Bouaouina, H., A. Desrumaux, C. Loisel, and J. Legrand. 2006. Functional properties of whey proteins as affected by dynamic highpressure treatment. Int. Dairy J. 16:275-284.

Britten, M., H. J. Giroux, and V. Gaudin. 1994. Effect of pH during heat processing on partially hydrolyzed whey protein. J. Dairy Sci. 77:676-684.

Cadwallader, K. R., T. K. Singh, and J. P. Jerell. 2007. Streamlined analysis of short, medium, and long chain free fatty acids in dairy products. Pages 111-133 in Flavor of Dairy Products. K. R. Cadwallader, M. A. Drake, and R. J. McGorrin, ed. ACS, Washington, DC.

Carunchia Whetstine, M. E., J. D. Parker, M. A. Drake, and D. K. Larick. 2003. Determining flavor and flavor variability in commercially produced liquid Cheddar whey. J. Dairy Sci. 86:439-448.

Collins, Y. F., P. L. H. McSweeney, and M. G. Wilkinson. 2004. Lipolysis and catabolism of fatty acids in cheese. Pages $373-389$ in Cheese: Chemistry, Physics, and Microbiology. P. F. Fox, P. L. 
H. McSweeney, T. M. Cogan, and T. P. Guinee ed. Elsevier, San Diego, CA.

Croissant, A. E., E. J. Kang, R. E. Campbell, E. Bastian, and M. A. Drake. 2009. The effect of bleaching agent on the flavor of liquid whey and whey protein concentrate. J. Dairy Sci. 92:5917-5927.

Croissant, A. E., S. P. Washburn, L. L. Dean, and M. A. Drake. 2007. Chemical properties and consumer perception of fluid milk from conventional and pasture-based production systems. J. Dairy Sci. 90:4942-4953.

deWit, J. N., and G. Klarenbeek. 1984. Effects of various heat treatments on structure and solubility of whey proteins. J. Dairy Sci. $67: 2701-2710$

Drake, M. A. 2006. Flavor and flavor carry-through of whey proteins in beverages. Pages 292-300 in The Wonders of Whey... Catch the Power. Proc. 4th Int. Whey Protein Conf., ADPI, Elmhurst, IL. Federation of Animal Science Societies, Savoy, IL.

Drake, M. A., Y. Karagul, K. R. Yuceer, G.V. Cadwallader, Civille, and P. S. Tong. 2003. Determination of the sensory attributes of dried milk powders and dairy ingredients. J. Sens. Stud. 18:199216

Drake, M. A., R. E. Miracle, and J. M. Wright. 2009. Sensory properties of dairy proteins. Pages 429-448 in Milk Proteins: From Expression to Food. A. Thompson, M. Boland, and H. Singh, ed. Elsevier, New York, NY.

Frankel, E. N. 1998. Lipid Oxidation. 1st ed. The Oily Press, Dundee, UK.

Galindo-Cuspinera, V., M. B. Lubran, and S. A. Rankin. 2002. Comparison of volatile compounds in water-and-oil-soluble annatto (Bixa orellana L.) extracts. J. Agric. Food Chem. 50:2010-2015.

Gallardo-Escamilla, F. J., A. L. Kelly, and C. M. Delahunty. 2005. Sensory characteristics and related volatile flavor compound profiles of different types of whey. J. Dairy Sci. 88:2689-2699.

Javidipour, I., and M. C. Qian. 2008. Volatile component change in whey protein concentrate during storage investigated by headspace solid-phase microextraction gas chromatography. Dairy Sci. Technol. 88:95-104.

Jayaprakasha, H. M., and H. Brueckner. 1999. Whey protein concentrate: A potential functional ingredient for food industry. J. Food Sci. Technol. 36:189-204.
Kang, E. J., R. E. Campbell, E. Bastian, and M. A. Drake. 2010. Invited review: Annatto and bleaching in dairy foods. J. Dairy Sci. 93:3891-3901.

Kiokias, S., and M. H. Gordon. 2003. Antioxidant properties of annatto carotenoids. Food Chem. 83:523-529.

Levy, L. W., and D. M. Rivadeneira. 2000. Annatto. Pages 115-152 in Natural Food Colorants. G. J. Lauro and F. J. Francis, ed. Marcel Dekker Inc., New York, NY.

Liaw, I. W., H. Eshpari, P. S. Tong, and M. A. Drake. 2010. The impact of antioxidant addition on flavor of Cheddar and Mozzarella whey and Cheddar whey protein concentrate. J. Food Sci. 75:C559-C569.

Lloyd, M. A., S. J. Hess, and M. A. Drake. 2009. Effect of nitrogen flushing and storage temperature on flavor and shelf-life of whole milk powder. J. Dairy Sci. 92:2409-2422.

Meilgaard, M. C., G. V. Civille, and B. T. Carr. 2007. The Spectrum descriptive analysis method. Pages 189-253 in Sensory Evaluation Techniques. CRC Press, Boca Raton, FL.

Mercadante, A. Z. 2008. Analysis of carotenoids. Pages $447-478$ in Food Colorants: Chemical and Functional Properties. C. Socaciu, ed. CRC Press, Boca Raton, FL.

Scotter, M. 2009. The chemistry and analysis of annatto food coloring: A review. Food Addit. Contam. 26:1123-1145.

Smith, P. K., R. I. Krohn, G. T. Hermansson, A. K. Mallia, F. H Gartner, and M. D. Provenzano. 1985. Measurement of protein using bicinchoninic acid. Anal. Biochem. 150:76-85.

Tomaino, R. M., L. G. Turner, and D. K. Larick. 2004. The effect of Lactococcus lactis starter cultures on the oxidative stability of liquid whey. J. Dairy Sci. 87:300-307.

Van den Dool, H., and P. D. Kratz. 1963. A generalization of retention index system including linear temperature programmed gas-liquid partition chromatography. J. Chromatogr. A 11:463-467.

Whitson, M. E., R. E. Miracle, and M. A. Drake. 2010. Sensory characterization of chemical components responsible for cardboard flavor in whey protein. J. Sens. Stud. 25:616-636.

Wright, B. J., S. E. Zevchak, J. M. Wright, and M. A. Drake. 2009. The impact of agglomeration and storage on flavor and flavor stability of whey protein concentrate $80 \%$ and whey protein isolate. J. Food Sci. 74:S17-S29. 